\title{
Calidad del agua de distribución en un Centro Universitario rural sin procesos de desinfección de la Universidad de Guadalajara, México
}

\section{Water quality distribution in a rural university center without disinfection processes of the University of Guadalajara, Mexico}

\author{
GARCÍA-VELASCO, Javier ${ }^{1 * \dagger}$, VILLASEÑOR-VARGAS, Tania ${ }^{2}$, CASAS-SOLÍS, Josefina $^{2}$ y \\ ROSAS-RAMÍREZ, Aurora ${ }^{2}$
} ${ }^{1}$ Instituto de Medio Ambiente y Comunidades Humanas, Centro Universitario de Ciencias Biológicas y Agropecuarias.
Universidad de Guadalajara, México
${ }^{2}$ Lab. Microbiología Departamento de Biología Celular y Molecular. Centro Universitario de Ciencias Biológicas y
Agropecuarias. Universidad de Guadalajara, México

ID $1^{\text {er }}$ Autor: Javier, García-Velasco / ORC ID: 0000-0003-3042-7841, Researcher ID Thomson: T-4575-2018, CVU CONACYT ID: 252703

ID1 ${ }^{\text {er }}$ Coautor: Tania, Villaseñor-Vargas / ORC ID: 0000-0002-2472-1027, arVIX ID: TaniaVV, PubMed ID: 51e95e2407121cc0b9314d66cd425d340b08

ID $2^{\text {do }}$ Coautor: Josefina, Casas-Solis / ORC ID: 0000-0001-7880-7240, Researcher ID Thomson: U-1318-2018, CVU CONACYT ID: 218087

ID $3^{\text {er }}$ Coautor: Aurora, Rosas-Ramirez / ORC ID: 0000-0003-0710-6505, Researcher ID Thomson: T-7847-2018, CVU CONACYT ID: 311671

DOI: $10.35429 / J U S D .2019 .14 .5 .12 .20$

Recibido: 10 de Enero, 2019; Aceptado 30 de Marzo, 2019

\section{Resumen}

El Centro Universitario de Ciencias Biológicas y Agropecuarias (CUCBA) de la Universidad de Guadalajara recibe aproximadamente 5700 estudiantes, y 1500 del personal académico, administrativo y visitantes. El CUCBA está orientado a la investigación, por lo tanto, se genera una gran cantidad de desechos químicos y carga microbiana por los servicios sanitarios. Existen dos fuentes de suministro de agua que proporcionan agua potable de calidad a la población estudiantil y dos plantas de tratamiento de agua que procesan las aguas residuales producidas. El objetivo de este estudio fue evaluar la calidad físico química y bacteriológica del agua de las fuentes de suministro, tanques de almacenamiento, red de distribución y principales puntos de uso como área de alimentos y bebederos, así como las aguas residuales emitidas, por triplicado. Se calculó el índice de calidad del agua, y se encontraron valores regulares de la calidad del agua de los 10 puntos muestreados, y se resalta que, los puntos de muestreo con el índice de calidad más bajo fueron el agua que sale de las plantas de tratamiento de agua, por lo tanto, no se está cumpliendo con una depuración adecuada del agua.

Calidad del agua, Metales pesados, Coliformes totales y fecales

\begin{abstract}
The University Center of Biological and Agricultural Sciences (CUCBA) of the University of Guadalajara receives approximately 5700 students, and 1500 of the academic, administrative and visiting staff. The CUCBA is research oriented, therefore, a large amount of chemical waste and microbial load is generated by health services. There are two sources of water supply that provide quality drinking water to the student population and two water treatment plants that process the wastewater produced. The objective of this study was to evaluate the physical chemical and bacteriological quality of the water from the sources of supply, storage tanks, distribution network and principals points of use as an area of food and drinkers, as well as the wastewater emitted in triplicate. The water quality index was calculated, and regular values of the water quality of the 10 sampled points were found, and it is noted that, the sampling points with the lowest quality index were the water that leaves the plants of Water treatment, therefore, is not being accomplished with proper water purification.
\end{abstract}

Water quality, Heavy metals, Total and faecal coliforms

Citación: GARCÍA-VELASCO, Javier, VILLASEÑOR-VARGAS, Tania, CASAS-SOLÍS, Josefina y ROSAS-RAMÍREZ, Aurora. Calidad del agua de distribución en un Centro Universitario rural sin procesos de desinfección de la Universidad de Guadalajara, México. Revista del Desarrollo Urbano y Sustentable. 2019. 5-14: 12-20

*Correspondencia al autor (Correo electrónico: javier.gvelasco@academicos.udg.mx)

$\dagger$ Investigador contribuyendo como primer autor 


\section{Introducción}

En la determinación de la disponibilidad del agua en un país, no solamente es necesario saber qué cantidad de agua está al alcance en las diferentes fases del ciclo hidrológico, además, deben conocerse las características fisicoquímicas y bacteriológicas para estar en condiciones de darle uso en diferentes actividades productivas y como agua potable en el abastecimiento a poblaciones.

Calidad del agua es aquella "adecuada para consumo humano y para todo uso doméstico habitual, incluida la higiene personal". El agua debe estar libre de organismos patógenos, sustancias químicas, impurezas y cualquier tipo de contaminación que cause problemas a la salud humana. (OMS, 2006). La distribución de las poblaciones humanas está definida en gran medida por la disponibilidad de agua para el desarrollo de sus diversas actividades cotidianas, de producción de alimentos, de bienes y servicio y de esparcimiento (Guzmán y Merino, 1992).

La calidad del agua es importante, cuando la relacionamos con los posibles riesgos a la salud de los organismos vivos. La problemática actual derivada de la contaminación del recurso hídrico es amplia y compleja, tanto de aguas superficiales como subterráneas. Cuando los cuerpos de agua están contaminados, se presentan consecuentes afectaciones a la salud pública, a los recursos naturales, así como a la reducción de la disponibilidad del vital líquido. En 1994, las Naciones Unidas mencionan que el $30 \%$ de las muertes que se producen en el mundo en desarrollo y el $80 \%$ de las enfermedades de sus poblaciones, están relacionadas con la escasez de agua y su deficiente depuración. (UNESCO, 2003). El agua no se encuentra naturalmente en estado puro siempre contiene cierto número $\mathrm{y}$ cantidad de sustancias que provienen de diversas fuentes: la precipitación, su propia acción erosiva, el viento, su contacto con la atmósfera, y así, en las aguas que no han recibido vertidos artificiales se encuentran sólidos y coloides en suspensión (que afectan a la transparencia), solidos disueltos (que se reflejan en la alcalinidad, valor de $\mathrm{pH}$, dureza, conectividad), oxígeno disuelto (que influye decisivamente en la vida acuática), etc., los cuales constituyen caracteres y cualidades del agua.
El recurso del agua, constituye un elemento directamente relacionado con la salud de la población y del planeta en general y las medidas que busquen su conservación deben ser elementales en las políticas y acciones de todos los países a sus diferentes niveles de participación (Chávez, 1995). Entre las enfermedades de transmisión hídrica más conocidas figuran el cólera y otras enfermedades diarreicas. (Mariscal, 1995). La contaminación bacteriológica del agua provoca diarrea, retortijones, náuseas, cefaleas u otros síntomas.

Estos patógenos podrían representar un riesgo de salud muy importante para bebés, niños y personas con sistemas inmunológicos gravemente comprometidos. Por falta de suministro de agua a la población y/o medidas deficientes de higiene, pueden aparecer en los individuos enfermedades de la piel.

La contaminación química, en especial la generada por metales pesados, es particularmente peligrosa para la salud, con dosis toxicas bajas y asociada a toxicidad hepática y efectos cancerígenos. (Ballester, 1995). En cuanto al saneamiento, el agua puede contaminarse con aguas residuales o por sustancias químicas toxicas vertidas principalmente por la industria, los hospitales y los laboratorios químicos.

\section{Antecedentes}

El Centro Universitario de Ciencias Biológicas y Agropecuarias (CUCBA), forma parte de la red universitaria que la Universidad de Guadalajara tienen en todo el estado de Jalisco, Es un centro tematico y en el se imparten las carreras de Licenciado en Biológia, Médico Veterinário Zootecnista, Ingeniero Agronomo, Licenciatura en Ciencias de los Alimentos y Licenciado en Agronegocios. El Centro Universitario cuenta con aproximadamente 7,000 personas (a febrero de 2017), entre ellas 5,516 alumnos de licenciatura y 216 de posgrado, el $91 \%$ de los estudiantes de ellos cursan estudios de licenciatura en agronomía, biología y medicina veterinaria y se cuenta con 330 profesores de tiempo completo.

Al incrementarse la población humana, se ha acentuado aún más la contaminación del agua, ocasionando perjuicio a la salud pública. 
La pertinencia de realizar este trabajo está fundamentada en la evaluación de la calidad del agua derivada del incremento de la población (estudiantil, académicos, administrativos y de servicio) que actualmente llega a 8000 personas, que consumen y utiliza agua extraída de forma local, la cual no recibe tratamiento previo antes de su distribución en la red del centro universitario, y se desconocen sus implicaciones con la salud pública $\mathrm{y}$ ambiental.

En la poblacion mas cercana, Nextipac, existen evidencias de un análisis fisicoquímico de agua el cual se reportó como agua no potable por la presencia de nitritos y cobre con valores que excedieron los límites máximos permitidos por la norma (Secretaria de Recursos Hidráulicos, 1973). En julio de 1996 se llevó a cabo una evaluación de riesgos en el Centro Universitario de Ciencias Biológicas y Agropecuarias (CUCBA), en donde se hizo un diagnóstico de la calidad del agua, en donde se reportó la presencia de organismos coliformes totales, fecales y plomo con valores que exceden la norma oficial mexicana (López, 2001).

Se realizó otro estudio en los años 1998 y 1999 en el que se evaluó la calidad del agua y se hizo una identificación de riesgos a la salud en el Centro Universitario de Ciencias Biológicas y Agropecuarias, en donde se reportó que se considera deficiente y no apta para consumo humano, ya que se encontró la presencia de organismos coliformes totales y fecales además de Salmonella spp, lo cual representa un riesgo a la salud (López, 2001).

La contaminación del agua ocasionada por diversas fuentes, trae como consecuencias alteraciones en la salud humana, por lo tanto, es importante actualizar datos sobre la calidad del agua en el CUCBA.

\section{Metodología}

Esta investigación es de tipo observacional descriptivo longitudinal y se realizó en el período comprendido de enero a mayo de 2018 en el CUCBA de la Universidad de Guadalajara. Las características metodológicas de la investigación comprenden tres fases: (1) muestreo de agua y aire en los puntos seleccionados, (2) análisis de agua, (3) y la integración y evaluación de resultados, estadística descriptiva y graficación.
El Centro Universitario de Ciencias Biológicas y Agropecuarias de la Universidad de Guadalajara se encuentra ubicado en el Estado de Jalisco, en el Municipio de Zapopan, al noreste de la ciudad de Guadalajara. Desde el punto de vista geológico se ubica dentro de la provincia fisiográfica denominada Eje Volcánico (Faja Volcánica Mexicana), en las siguientes coordenadas geográficas, al Norte a $20^{\circ} 44^{\prime} 46.4^{\prime \prime}$ y al Oeste $103^{\circ} 30^{\prime} 40.8^{\prime \prime}$., como se muestra en la figura 1.

La fuente de agua que abastece actualmente al CUCBA proviene de un pozo construido en el año de 1976 con una profundidad de 200 metros, en el año 2014 se perforo un nuevo pozo, con una profundidad de 250 metros, el cual no es utilizado, se cuenta con dos cisternas de almacenamiento con capacidad de 60,000 y 30,000 litros, de las que se bombea a la red de distribución del Centro Universitario.

Se seleccionaron 12 puntos representativos: los pozos de extracción, la red de distribución del agua, tanques de almacenamiento, planta de tratamiento de aguas residuales y purificadora. El primer muestreo se realizó en el mes de enero, el segundo fue en inicios del mes de marzo y el último en el mes de mayo de 2018.

Para el muestreo se utilizaron materiales como: hojas de campo, etiquetas, marcadores indelebles, agua destilada, papel absorbente, hieleras, hielo, frascos de plástico de 3 litros, bolsas estériles para análisis microbiológico y reactivos diversos. Se determinó en cada sitio de muestreo la fecha, hora, nubosidad (cobertura y tipo), viento (velocidad), temperatura del aire, en cada estación se utilizó una Estación meteorológica portátil, marca Kestrel K $4500 ®$ especialmente diseñado para el monitoreo medioambiental, dicho instrumento funciona como: anemómetro, termómetro, higrómetro, altímetro y barómetro. Se midió transparencia, olor y color, temperatura, conductividad, $\mathrm{pH}$ y oxígeno disuelto. 


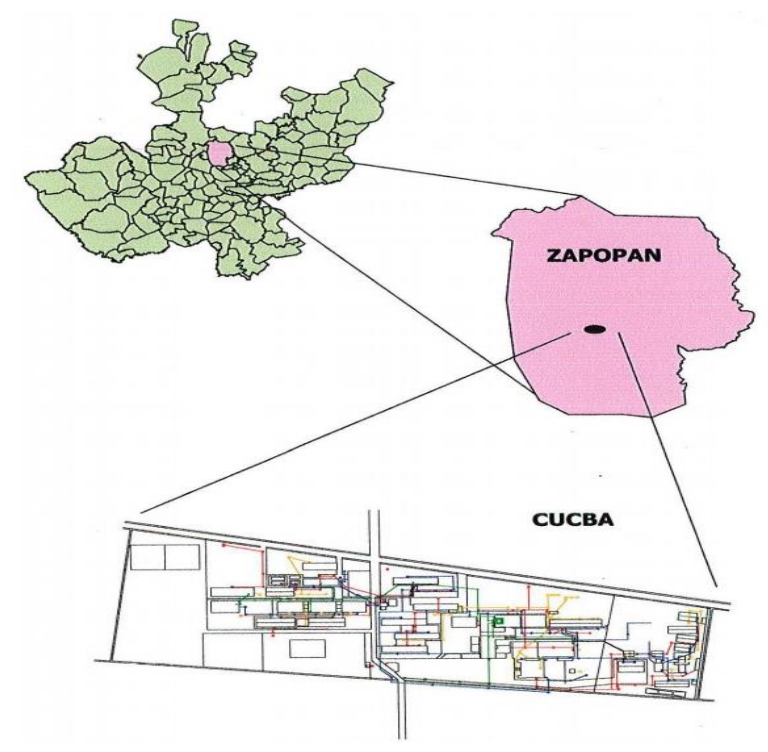

Figura 1 Ubicación de CUCBA

Fuente: Elaboración Propia

A continuación, se muestran los puntos de muestreo, su ubicación y coordenadas.

\begin{tabular}{|c|c|c|c|}
\hline No. & $\begin{array}{l}\text { Punto de } \\
\text { muestreo }\end{array}$ & Ubicación & Coordenadas \\
\hline 1 & Pozo & CUCBA & $\begin{array}{l}\text { N 2044'48',W } \\
103^{\circ} 30^{\prime} 49\end{array}$ \\
\hline 2 & $\begin{array}{l}\text { Tanques } \\
\text { almacenamiento }\end{array}$ & CUCBA & $\begin{array}{l}\text { N 204'ㄴ, } 51, \mathrm{~W} \\
103^{\circ} 30^{\prime} 47\end{array}$ \\
\hline 3 & Bebedero & $\begin{array}{l}\text { CUCBA, en la entrada de } \\
\text { puestos de comida }\end{array}$ & $\begin{array}{l}\text { N 204'ㄴ, } 50, \mathrm{~W} \\
103^{\circ} 30^{\prime} 42\end{array}$ \\
\hline 4 & Bebedero & CUCBA, en el edificio J & $\begin{array}{l}\text { N 204'ㄷ, } \mathrm{W} \\
103^{\circ} 30^{\prime} 49\end{array}$ \\
\hline 5 & Bebedero & $\begin{array}{l}\text { CUCBA, en antigua } \\
\text { rectoría }\end{array}$ & $\begin{array}{l}\text { N 204' } 46, \mathrm{~W} \\
103^{\circ} 30^{\prime} 43 \\
\end{array}$ \\
\hline 6 & Bebedero & $\begin{array}{l}\text { CUCBA, a un costado de } \\
\text { la michoacana }\end{array}$ & $\begin{array}{l}\text { N 2044’47, W } \\
103^{\circ} 30^{\prime} 40\end{array}$ \\
\hline 7 & Bebedero & $\begin{array}{l}\text { CUCBA, afuera de sala } \\
\text { de computo }\end{array}$ & $\begin{array}{l}\text { N 204'ㄴ, } 48, \mathrm{~W} \\
103^{\circ} 30^{\prime} 38\end{array}$ \\
\hline 8 & Llave de agua & CUCBA, edificio P & $\begin{array}{l}\mathrm{N} 20^{\circ} 44^{\prime} 49, \\
\mathrm{~W} 103^{\circ} 30^{\prime} 40\end{array}$ \\
\hline 9 & ATINNA & $\begin{array}{l}\text { CUCBA, En planta baja } \\
\text { del edificio }\end{array}$ & $\begin{array}{l}\text { N 2044'54, W } \\
103^{\circ} 30^{\prime} 66\end{array}$ \\
\hline 10 & Purificadora & $\begin{array}{l}\text { CUCBA, Atrás de sala de } \\
\text { computo }\end{array}$ & $\begin{array}{l}\text { N 2044'48, W } \\
103^{\circ} 30^{\prime} 39\end{array}$ \\
\hline 11 & Cafetería & $\begin{array}{l}\text { CUCBA, enfrente del } \\
\text { edificio A }\end{array}$ & $\begin{array}{l}\text { N 2044'47, W } \\
103^{\circ} 30^{\prime} 39\end{array}$ \\
\hline 12 & Planta tratadora & CUCBA & $\begin{array}{l}\text { N 2044’48, W } \\
103^{\circ} 30^{\prime} 35\end{array}$ \\
\hline
\end{tabular}

Tabla 1 Sitios de muestreo seleccionados en el CUCBA Fuente: Elaboración Propia.

El muestreo se realizó de acuerdo a la Norma Mexicana NMX-AA-014-1980, Cuerpos Receptores- Muestreo y la Norma Oficial Mexicana NOM-230-SSA1-2002, Salud ambiental. Agua para uso y consumo humano, requisitos sanitarios que se deben cumplir en los sistemas de abastecimiento públicos y privados durante el manejo del agua. Procedimientos sanitarios para el muestreo.
En cada uno de los parámetros analizados se determinó previamente el límite mínimo de detección, así como las pruebas correspondientes a la precisión y exactitud, procediendo a su aplicación de acuerdo a los lineamientos que para cada caso en particular existen en la literatura

\section{Cálculo del Índice de Calidad del Agua (ICAS)}

Para el cálculo del índice de calidad del agua, ICA, se utilizó la metodología propuesta por Martínez de Bascarán (1979), que permite obtener un valor variable de 0 a 100 como ICA, si el agua es buena, su valor será próximo a 100, y cuanto peor sea, más bajo será dicho número. Para elaborar el ICA, se seleccionaron aquellos parámetros de calidad del agua más usuales en la evaluación de lagos y que se enumeran en los Criterios Ecológicos de Calidad del Agua (CE-CCA-001-89) así como los utilizados en la NOM-127-SSA1-1994 y como: $\mathrm{pH}$, cloruros, conductividad, dureza total, turbiedad, nitratos, sulfatos, nitritos, Sólidos Disueltos Totales y temperatura, entre otros.

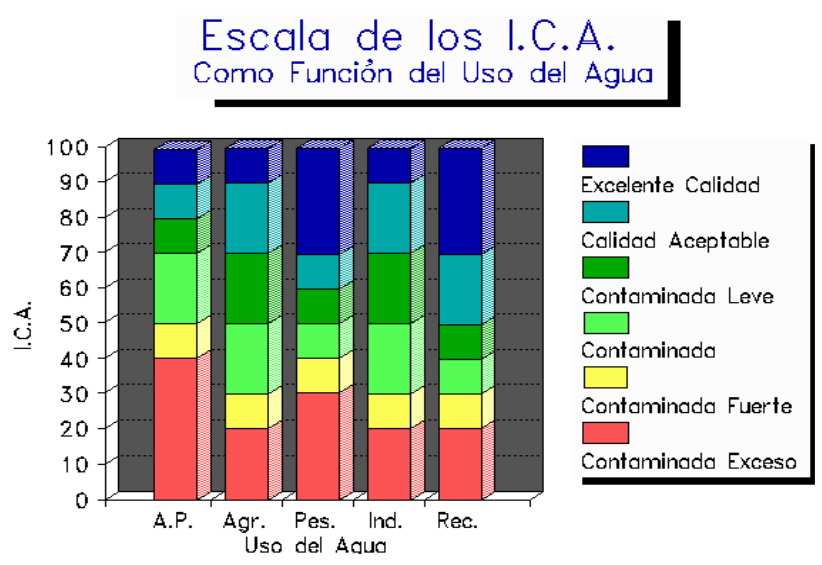

Figura 2 Rangos de clasificación del agua por el ICA en función al uso del agua

Fuente: Martínez, 1979.

El grado de contaminación del agua es clasificado en términos del índice calculado y los tratamientos que se requieren como se observa en la tabla 2. 


\begin{tabular}{|c|c|c|c|}
\hline $\begin{array}{l}\text { Rango } \\
\text { (ICA) }\end{array}$ & Clasificación & Observaciones & Clave \\
\hline $\begin{array}{l}90.1 \mathrm{a} \\
100.0\end{array}$ & Excelente & $\begin{array}{l}\text { No requiere } \\
\text { tratamiento }\end{array}$ & Ex \\
\hline $\begin{array}{l}80.1 \mathrm{a} \\
90.0\end{array}$ & Aceptable & $\begin{array}{l}\text { Requiere de } \\
\text { tratamiento menor }\end{array}$ & Ac \\
\hline $\begin{array}{l}70.1 \mathrm{a} \\
80.0\end{array}$ & Leve contaminada & $\begin{array}{l}\text { Requiere de } \\
\text { tratamiento }\end{array}$ & $\mathrm{Lc}$ \\
\hline $\begin{array}{l}50.1 \mathrm{a} \\
70.0\end{array}$ & Contaminada & $\begin{array}{l}\text { Requiere } \\
\text { necesariamente de } \\
\text { tratamiento }\end{array}$ & $\mathrm{Co}$ \\
\hline $\begin{array}{l}40.1 \mathrm{a} \\
50.0\end{array}$ & $\begin{array}{l}\text { Fuertemente } \\
\text { contaminada }\end{array}$ & Riesgo al consumirla & $\mathrm{Fc}$ \\
\hline 0 a 40.0 & $\begin{array}{l}\text { Excesivamente } \\
\text { contaminada }\end{array}$ & $\begin{array}{l}\text { Inaceptable para } \\
\text { consumo }\end{array}$ & $\mathrm{Ec}$ \\
\hline
\end{tabular}

Tabla 2 Rangos del Índice de Calidad del Agua (Agua potable para consumo humano)

Fuente: Ordenamiento Ecológico Territorial Jalisco, 1997

Para estimar el índice de calidad del agua primero se normalizan los valores individuales que conforman el índice al establecer una correspondencia de los resultados obtenidos en cada uno de los análisis con una escala variable de 0 a 100.

Se asigna un peso numérico a cada uno de los parámetros indicando de acuerdo con su importancia en los criterios normales de calidad. La determinación del peso de un parámetro se realiza en forma conjunta con un equipo especializado en la calidad del agua mediante la aplicación del método Delphi se llega a un resultado estimativo de, pero para cada uno de ellos. Obtenidos los resultados del valor en escala de 0 a 100 y el peso asignado a cada uno, se aplica la siguiente fórmula para el cálculo del índice de calidad del agua.

$I C A=\frac{\sum \mathrm{CiPi}}{\sum \mathrm{Pi}} k$

Dónde:

$\mathrm{Ci}=$ Valor porcentual asignado a los parámetros $\mathrm{Pi}=$ Peso asignado a cada parámetro

$\mathrm{K}=$ Constante que varía de 1 a 0.25 según la contaminación aparente del agua, definida de la siguiente forma:

\subsection{Para aguas claras sin aparente contaminación}

0.75 Para aguas con ligero color, con espuma y ligera turbiedad, aparentemente no natural.

0.50 Para aguas con apariencia de estar contaminadas y con fuerte olor.
0.25 para aguas negras que presentan fermentaciones y olores.

El peso de los parámetros está indicado de acuerdo con su importancia en los criterios normales de calidad. En la determinación del peso de un parámetro (Tabla 3) se utiliza el criterio de acuerdo a la toxicidad del parámetro a determinar. En el proceso de cálculo numérico se aplicó en la fórmula de ICA un valor para la constante $\mathrm{k}$ de 1.0 considerando que es agua clara sin aparente contaminación.

\begin{tabular}{|l|l|}
\hline \multicolumn{1}{|c|}{ Valor asignado } & Parámetro \\
\hline Valor máximo de 4 & Arsénico \\
\hline & Cadmio \\
\hline & Mercurio \\
\hline & Plomo \\
\hline & Níquel \\
\hline & N de Nitritos \\
\hline & N amoniacal \\
\hline & Coliformes fecales \\
\hline & Salmonella ssp \\
\hline & Shigella ssp \\
\hline Valor medio de 3 & Plaguicidas \\
\hline & Cobre \\
\hline & Hierro \\
\hline & Manganeso \\
\hline & Dureza total \\
\hline & Coliformes totales \\
\hline Valor menor de 2 & Turbiedad \\
\hline & Color \\
\hline & Conductividad \\
\hline & Alcalinidad \\
\hline Valor mínimo de 1 & pH \\
\hline & Cloruros \\
\hline & SDT \\
\hline & \\
\hline &
\end{tabular}

Tabla 3 Peso asignado a los parámetros

Fuente: Martínez, 1976

Para el análisis legal se utilizo las Normas Oficiales Mexicanas vigentes, como son:

- NOM-127-SSA1-1994,

Salud ambiental. Agua para uso y consumo humano. Límites permisibles de calidad y tratamientos a que debe someterse el agua para su potabilización.

Criterios Ecológicos de Calidad del Agua CE-CCA-001-89 Fecha de publicación en Diario Oficial 13 de diciembre de 1989, Fecha de entrada en vigor 14 de diciembre de 1989. Fuente de Abastecimiento.

\section{Resultados}

Se describe el indice de calidad del agua para los tres muestreos realizados. 


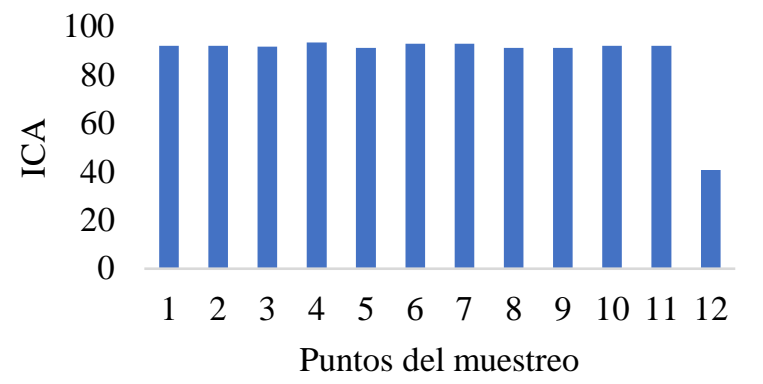

Figura 3 Índice de Calidad del Agua, muestreo 1 (enero) Fuente: Elaboración Propia

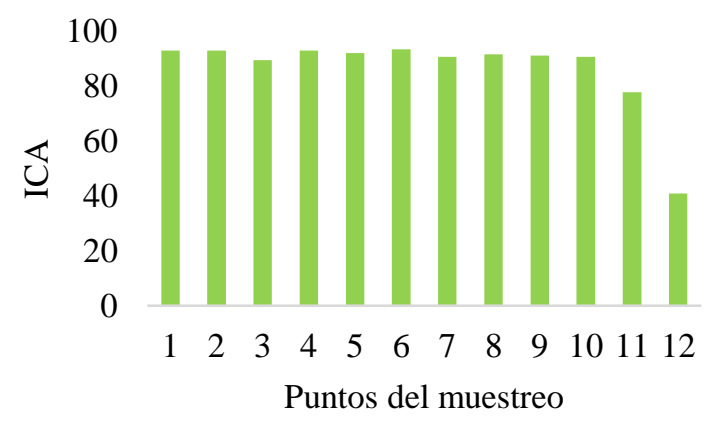

Figura 4 Índice de Calidad del Agua, muestreo 2 (marzo) Fuente: Elaboración Propia

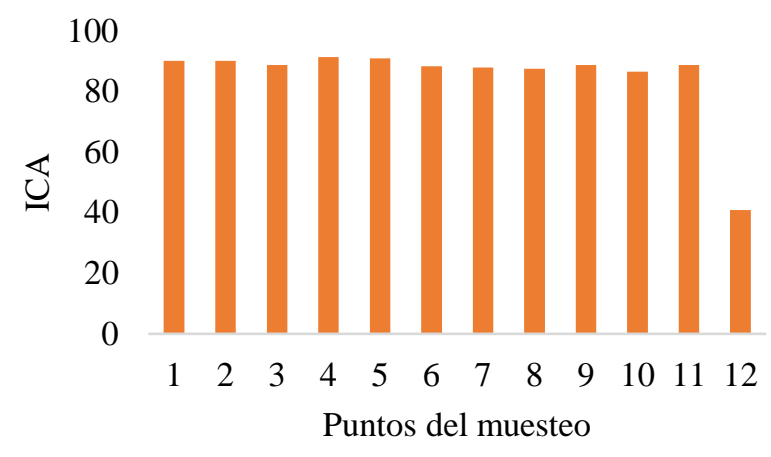

Figura 4 Índice de Calidad del Agua, muestreo 3 (mayo) Fuente: Elaboración Propia

\begin{tabular}{|c|c|c|c|c|c|c|}
\hline $\begin{array}{l}\text { Punto de } \\
\text { muestre } \\
\text { o }\end{array}$ & ICA & $\begin{array}{c}\text { Agua } \\
\text { potable }\end{array}$ & Uso agrícola & $\begin{array}{l}\text { Pesca y vida } \\
\text { acuática }\end{array}$ & $\begin{array}{c}\text { Uso } \\
\text { industrial }\end{array}$ & $\begin{array}{l}\text { Uso } \\
\text { recreativo }\end{array}$ \\
\hline 1 & $\begin{array}{l}92.1 \\
7\end{array}$ & $\begin{array}{l}\begin{array}{l}\text { Excelente } \\
\text { calidad }\end{array} \\
\end{array}$ & $\begin{array}{l}\begin{array}{l}\text { Excelente } \\
\text { calidad }\end{array} \\
\end{array}$ & $\begin{array}{l}\text { Excelente } \\
\text { calidad }\end{array}$ & $\begin{array}{l}\begin{array}{l}\text { Excelente } \\
\text { calidad }\end{array} \\
\end{array}$ & $\begin{array}{l}\begin{array}{l}\text { Excelente } \\
\text { calidad }\end{array} \\
\end{array}$ \\
\hline 2 & $\begin{array}{l}92.1 \\
7\end{array}$ & $\begin{array}{l}\text { Excelente } \\
\text { calidad }\end{array}$ & $\begin{array}{l}\text { Excelente } \\
\text { calidad }\end{array}$ & $\begin{array}{l}\text { Excelente } \\
\text { calidad }\end{array}$ & $\begin{array}{l}\text { Excelente } \\
\text { calidad }\end{array}$ & $\begin{array}{l}\text { Excelente } \\
\text { calidad }\end{array}$ \\
\hline 3 & $\begin{array}{l}91.7 \\
3\end{array}$ & $\begin{array}{l}\text { Excelente } \\
\text { calidad }\end{array}$ & $\begin{array}{l}\text { Excelente } \\
\text { calidad }\end{array}$ & $\begin{array}{l}\text { Excelente } \\
\text { calidad }\end{array}$ & $\begin{array}{l}\text { Excelente } \\
\text { calidad }\end{array}$ & $\begin{array}{l}\text { Excelente } \\
\text { calidad }\end{array}$ \\
\hline 4 & $\begin{array}{l}93.4 \\
7\end{array}$ & $\begin{array}{l}\begin{array}{l}\text { Excelente } \\
\text { calidad }\end{array} \\
\end{array}$ & $\begin{array}{l}\begin{array}{l}\text { Excelente } \\
\text { calidad }\end{array} \\
\end{array}$ & $\begin{array}{l}\text { Excelente } \\
\text { calidad }\end{array}$ & $\begin{array}{l}\begin{array}{l}\text { Excelente } \\
\text { calidad }\end{array} \\
\end{array}$ & $\begin{array}{l}\text { Excelente } \\
\text { calidad }\end{array}$ \\
\hline 5 & $\begin{array}{l}91.3 \\
0\end{array}$ & $\begin{array}{l}\text { Excelente } \\
\text { calidad }\end{array}$ & $\begin{array}{l}\text { Excelente } \\
\text { calidad }\end{array}$ & $\begin{array}{l}\text { Excelente } \\
\text { calidad }\end{array}$ & $\begin{array}{l}\text { Excelente } \\
\text { calidad }\end{array}$ & $\begin{array}{l}\text { Excelente } \\
\text { calidad }\end{array}$ \\
\hline 6 & $\begin{array}{l}93.0 \\
4\end{array}$ & $\begin{array}{l}\text { Excelente } \\
\text { calidad }\end{array}$ & $\begin{array}{l}\text { Excelente } \\
\text { calidad }\end{array}$ & $\begin{array}{l}\text { Excelente } \\
\text { calidad }\end{array}$ & $\begin{array}{l}\text { Excelente } \\
\text { calidad }\end{array}$ & $\begin{array}{l}\text { Excelente } \\
\text { calidad }\end{array}$ \\
\hline 7 & $\begin{array}{l}93.0 \\
4\end{array}$ & $\begin{array}{l}\text { Excelente } \\
\text { calidad }\end{array}$ & $\begin{array}{l}\text { Excelente } \\
\text { calidad }\end{array}$ & $\begin{array}{l}\text { Excelente } \\
\text { calidad }\end{array}$ & $\begin{array}{l}\text { Excelente } \\
\text { calidad }\end{array}$ & $\begin{array}{l}\text { Excelente } \\
\text { calidad }\end{array}$ \\
\hline 8 & $\begin{array}{l}91.3 \\
0\end{array}$ & $\begin{array}{l}\text { Excelente } \\
\text { calidad }\end{array}$ & $\begin{array}{l}\text { Excelente } \\
\text { calidad }\end{array}$ & $\begin{array}{l}\text { Excelente } \\
\text { calidad }\end{array}$ & $\begin{array}{l}\text { Excelente } \\
\text { calidad }\end{array}$ & $\begin{array}{l}\text { Excelente } \\
\text { calidad }\end{array}$ \\
\hline 9 & $\begin{array}{l}91.3 \\
0\end{array}$ & $\begin{array}{l}\text { Excelente } \\
\text { calidad }\end{array}$ & $\begin{array}{l}\text { Excelente } \\
\text { calidad }\end{array}$ & $\begin{array}{l}\text { Excelente } \\
\text { calidad }\end{array}$ & $\begin{array}{l}\text { Excelente } \\
\text { calidad }\end{array}$ & $\begin{array}{l}\text { Excelente } \\
\text { calidad }\end{array}$ \\
\hline 10 & $\begin{array}{l}92.1 \\
7\end{array}$ & $\begin{array}{l}\text { Excelente } \\
\text { calidad }\end{array}$ & $\begin{array}{l}\text { Excelente } \\
\text { calidad }\end{array}$ & $\begin{array}{l}\text { Excelente } \\
\text { calidad }\end{array}$ & $\begin{array}{l}\text { Excelente } \\
\text { calidad }\end{array}$ & $\begin{array}{l}\text { Excelente } \\
\text { calidad }\end{array}$ \\
\hline 11 & $\begin{array}{l}92.1 \\
7\end{array}$ & $\begin{array}{l}\text { Excelente } \\
\text { calidad }\end{array}$ & $\begin{array}{l}\text { Excelente } \\
\text { calidad }\end{array}$ & $\begin{array}{l}\text { Excelente } \\
\text { calidad }\end{array}$ & $\begin{array}{l}\text { Excelente } \\
\text { calidad }\end{array}$ & $\begin{array}{l}\text { Excelente } \\
\text { calidad }\end{array}$ \\
\hline 12 & $\begin{array}{l}40.8 \\
6\end{array}$ & $\begin{array}{l}\text { Contaminad } \\
\text { a }\end{array}$ & $\begin{array}{l}\text { Contaminad } \\
\text { a }\end{array}$ & $\begin{array}{l}\text { Contaminad } \\
\text { a }\end{array}$ & $\begin{array}{l}\text { Contaminad } \\
\text { a }\end{array}$ & $\begin{array}{l}\text { Contaminad } \\
\text { a leve }\end{array}$ \\
\hline
\end{tabular}

Tabla 4 Limitantes de uso en la calidad del agua, muestreo 1, de acuerdo a Bascarán, 1979

Fuente: Elaboración Propia

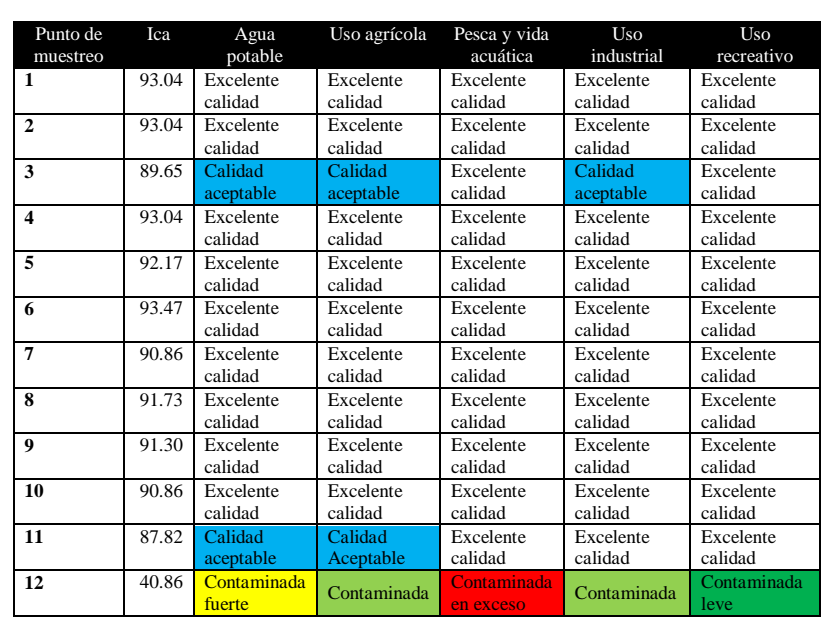

Tabla 5 Limitantes de uso en la calidad del agua, muestreo 2, de acuerdo a Báscaran, 1979

Fuente: Elaboración Propia

\begin{tabular}{|c|c|c|c|c|c|c|}
\hline $\begin{array}{l}\text { Punto de } \\
\text { muestreo }\end{array}$ & Ica & $\begin{array}{c}\text { Agua } \\
\text { potable }\end{array}$ & Uso agrícola & $\begin{array}{l}\text { Pesca y vida } \\
\text { acuática }\end{array}$ & $\begin{array}{c}\text { Uso } \\
\text { industrial }\end{array}$ & $\begin{array}{c}\text { Uso } \\
\text { recreativo }\end{array}$ \\
\hline 1 & 90 & $\begin{array}{l}\begin{array}{l}\text { Excelente } \\
\text { calidad }\end{array} \\
\end{array}$ & $\begin{array}{l}\text { Excelente } \\
\text { calidad }\end{array}$ & $\begin{array}{l}\text { Excelente } \\
\text { calidad }\end{array}$ & \begin{tabular}{|l|}
$\begin{array}{l}\text { Excelente } \\
\text { calidad }\end{array}$ \\
\end{tabular} & $\begin{array}{l}\text { Excelente } \\
\text { calidad }\end{array}$ \\
\hline 2 & 90 & $\begin{array}{l}\text { Excelente } \\
\text { calidad }\end{array}$ & $\begin{array}{l}\text { Excelente } \\
\text { calidad }\end{array}$ & $\begin{array}{l}\text { Excelente } \\
\text { calidad }\end{array}$ & $\begin{array}{l}\text { Excelente } \\
\text { calidad }\end{array}$ & $\begin{array}{l}\text { Excelente } \\
\text { calidad }\end{array}$ \\
\hline 3 & 88.69 & $\begin{array}{l}\text { Calidad } \\
\text { aceptable }\end{array}$ & $\begin{array}{l}\text { Calidad } \\
\text { aceptable }\end{array}$ & $\begin{array}{l}\text { Excelente } \\
\text { calidad }\end{array}$ & $\begin{array}{l}\text { Calidad } \\
\text { aceptable }\end{array}$ & $\begin{array}{l}\text { Excelente } \\
\text { calidad }\end{array}$ \\
\hline 4 & 91.30 & $\begin{array}{l}\text { Excelente } \\
\text { calidad }\end{array}$ & $\begin{array}{l}\text { Excelente } \\
\text { calidad }\end{array}$ & $\begin{array}{l}\text { Excelente } \\
\text { calidad }\end{array}$ & $\begin{array}{l}\text { Excelente } \\
\text { calidad }\end{array}$ & $\begin{array}{l}\text { Excelente } \\
\text { calidad }\end{array}$ \\
\hline 5 & 90.86 & $\begin{array}{l}\text { Excelente } \\
\text { calidad }\end{array}$ & $\begin{array}{l}\text { Excelente } \\
\text { calidad }\end{array}$ & $\begin{array}{l}\begin{array}{l}\text { Excelente } \\
\text { calidad }\end{array} \\
\end{array}$ & $\begin{array}{l}\text { Excelente } \\
\text { calidad }\end{array}$ & $\begin{array}{l}\text { Excelente } \\
\text { calidad }\end{array}$ \\
\hline 6 & 88.26 & $\begin{array}{l}\text { Calidad } \\
\text { aceptable }\end{array}$ & $\begin{array}{l}\text { Calidad } \\
\text { aceptable }\end{array}$ & $\begin{array}{l}\begin{array}{l}\text { Excelente } \\
\text { calidad }\end{array} \\
\text { (a) }\end{array}$ & $\begin{array}{l}\text { Calidad } \\
\text { aceptable }\end{array}$ & $\begin{array}{l}\begin{array}{l}\text { Excelente } \\
\text { calidad }\end{array} \\
\end{array}$ \\
\hline 7 & 87.82 & $\begin{array}{l}\text { Calidad } \\
\text { aceptable }\end{array}$ & $\begin{array}{l}\text { Calidad } \\
\text { aceptable }\end{array}$ & $\begin{array}{l}\text { Excelente } \\
\text { calidad }\end{array}$ & $\begin{array}{l}\text { Calidad } \\
\text { aceptable }\end{array}$ & $\begin{array}{l}\text { Excelente } \\
\text { calidad }\end{array}$ \\
\hline 8 & 87.39 & \begin{tabular}{|l|} 
Calidad \\
aceptable
\end{tabular} & $\begin{array}{l}\text { Calidad } \\
\text { aceptable }\end{array}$ & $\begin{array}{l}\text { Excelente } \\
\text { calidad }\end{array}$ & $\begin{array}{l}\text { Calidad } \\
\text { aceptable }\end{array}$ & $\begin{array}{l}\text { Excelente } \\
\text { calidad }\end{array}$ \\
\hline 9 & 88.69 & $\begin{array}{l}\text { Calidad } \\
\text { aceptable }\end{array}$ & $\begin{array}{l}\text { Calidad } \\
\text { aceptable }\end{array}$ & $\begin{array}{l}\begin{array}{l}\text { Excelente } \\
\text { calidad }\end{array} \\
\end{array}$ & $\begin{array}{l}\text { Calidad } \\
\text { aceptable }\end{array}$ & $\begin{array}{l}\begin{array}{l}\text { Excelente } \\
\text { calidad }\end{array} \\
\end{array}$ \\
\hline 10 & 86.52 & $\begin{array}{l}\text { Calidad } \\
\text { aceptable }\end{array}$ & $\begin{array}{l}\text { Calidad } \\
\text { aceptable }\end{array}$ & $\begin{array}{l}\begin{array}{l}\text { Excelente } \\
\text { calidad }\end{array} \\
\text { (a) }\end{array}$ & $\begin{array}{l}\text { Calidad } \\
\text { aceptable }\end{array}$ & $\begin{array}{l}\text { Excelente } \\
\text { calidad }\end{array}$ \\
\hline 11 & 88.69 & $\begin{array}{l}\text { Calidad } \\
\text { aceptable }\end{array}$ & $\begin{array}{l}\text { Calidad } \\
\text { aceptable }\end{array}$ & $\begin{array}{l}\text { Excelente } \\
\text { calidad }\end{array}$ & $\begin{array}{l}\text { Calidad } \\
\text { aceptable }\end{array}$ & $\begin{array}{l}\text { Excelente } \\
\text { calidad }\end{array}$ \\
\hline 12 & 40.86 & Contaminada & Contaminada & Contaminada & Contaminada & $\begin{array}{l}\text { Contaminada } \\
\text { leve }\end{array}$ \\
\hline
\end{tabular}

Tabla 6 Limitantes de uso en la calidad del agua, muestreo 3, de acuerdo a Báscaran, 1979

Fuente: Elaboración Propia

\section{Discusión}

El agua hace posible un medio ambiente saludable pero, paradójicamente, también puede ser el principal vehículo de transmisión de enfermedades. Las enfermedades transmitidas por el agua son enfermedades producidas por el "agua sucia" - las causadas por el agua que se ha contaminado con desechos humanos, animales o químicos. Mundialmente, la falta de servicios de evacuación sanitaria de desechos y de agua limpia para beber, cocinar y lavar es la causa de más de 12 millones de defunciones por año.

El grado de desarrollo poblacional alcanzado en la Universidad ha ocasionado problemas de contaminación de agua, en los laboratorios no hay un control de los desechos de reactivos y van directo al desagüe lo cual no tiene un tratamiento adecuado. 
Dentro del presente estudio se observa que la contaminación es evidente y existe a lo largo de los puntos de muestreo. En cuanto a contaminación fisicoquímica, se tienen estudios previos, demostrando con ello la contaminación existente desde hace ya varias décadas y con ello la falta de atención de las autoridades hacia este grave problema.

Además algunos puntos de muestreo presentan coliformes fecales las cuales limitan su uso como agua de consumo humano. Tomando este estudio como referencia podemos observar con el presente trabajo que las condiciones del agua de CUCBA han ido mejorando pues de acuerdo a los resultados obtenido tenemos que para todos los análisis fisicoquímicos y metales pesados, se observa que el agua se encuentra dentro de la clasificación de (aguas muy productivas).

Tomando como referencia con respecto a la media aritmética representativa en todo el muestreo, se observa que ningún parámetro sobrepasa el valor máximo estipulado en la leguilacioón vigente, exceptuado los coliformes totales y fecales. Los resultados en el seguimiento muestran un porcentaje de $13 \%$ de sitios con Coliformes Fecales y para Coliformes Totales de un 33\%, lo que no permite su utilización para ninguno los usos y además constituye un foco de exposición y riesgo bacteriológico a personas y animales.

Dentro del presente estudio se encontraron concentraciones muy pequeñas de metales pesados a lo largo de todos los puntos de muestreo, los metales que se encontraron con una cantidad insignificantica son los siguientes: cobre, sodio, hierro, manganeso y zinc.

\section{Análisis del Índice de Calidad del Agua}

el índice de calidad del agua como método estandarizado para poder evaluar la condición del agua de manera integral muestra de una manera más precisa las condiciones en las que se encuentra la calidad de agua evaluada en la tabla 7 .

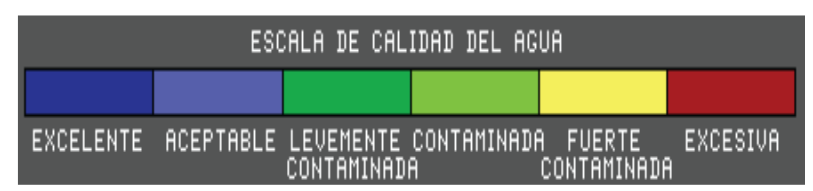

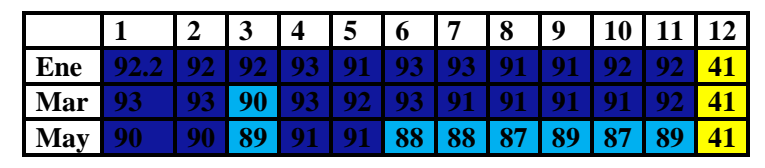

Tabla 7 Clasificación de la calidad del agua encontrada en el estudio en forma de ICA

Fuente: Elaboración Propia

De acuerdo con los resultados que se muestran en la tabla 8 , indican que la calidad del agua para uso y consumo del CUCBA en cuanto a composicion quimica mantiene su calidad aceptable, no asi la parte bacteriológica.

\begin{tabular}{|c|c|c|c|c|c|c|}
\hline & $\begin{array}{l}2001 \\
\text { pozo }\end{array}$ & $\begin{array}{l}2018 \\
\text { pozo }\end{array}$ & $\begin{array}{c}2001 \\
\text { tanque }\end{array}$ & $\begin{array}{c}2018 \\
\text { tanque }\end{array}$ & $\begin{array}{c}2001 \\
\text { red }\end{array}$ & $\begin{array}{c}2018 \\
\text { Red }\end{array}$ \\
\hline Alcalinidad total $(\mathrm{mg} / \mathrm{L})$ & 45.49 & 33.3 & 41.68 & 24.3 & 34.08 & 18.6 \\
\hline Cloruros $(\mathrm{mg} / \mathrm{L})$ & 5.69 & 7.94 & 6.63 & 25.8 & 6.73 & 7.93 \\
\hline Color (UPC) & 0.17 & 0 & 0.17 & 0 & 0.17 & 0 \\
\hline Conductividad $(\mu \mathrm{S})$ & 114.98 & 6.7 & 133.8 & 10.3 & 116.95 & 10.32 \\
\hline Dureza total $(\mathrm{mg} / \mathrm{L})$ & 9.1 & 24.6 & 12.07 & 5.3 & 14.74 & 9.3 \\
\hline Nitritos $(\mathrm{mg} / \mathrm{L})$ & 0.0009 & 0.009 & 0.001 & 0.07 & 0.001 & 0.016 \\
\hline $\mathrm{pH}(\mathrm{mg} / \mathrm{L})$ & 6.95 & 7.11 & 7.44 & 7.13 & 7.34 & 7.03 \\
\hline Solidos disueltos totales $(\mathrm{mg} / \mathrm{L})$ & 0.17 & 50.9 & 0.19 & 53.5 & 0.14 & 55 \\
\hline turbiedad (UTN) & 0.39 & 0.8 & 0.59 & 0.27 & 0.68 & 0.45 \\
\hline $\begin{array}{l}\text { Organismos coliformes totales } \\
(\mathrm{NMP} / 100 \mathrm{ml})\end{array}$ & 2 & 1 & 27 & 1 & 80 & 1 \\
\hline $\begin{array}{l}\text { Organismos coliformes fecales } \\
\text { (NMP/100 ml) }\end{array}$ & 2 & 1 & 54 & 1 & 76 & 1 \\
\hline Arsénico $(\mathrm{mg} / \mathrm{L})$ & 0.001 & 0 & 0.001 & 0 & 0.001 & 0 \\
\hline Cadmio $(\mathrm{mg} / \mathrm{L})$ & 0.001 & 0 & 0.001 & 0 & 0.001 & 0 \\
\hline Cobre $(\mathrm{mg} / \mathrm{L})$ & 0.01 & 0.01 & 0.01 & 0.01 & 4.87 & 0.013 \\
\hline Hierro $(\mathrm{mg} / \mathrm{L})$ & 0.1 & 0.50 & 0.02 & 0.11 & 0.01 & 0.12 \\
\hline Manganeso $(\mathrm{mg} / \mathrm{L})$ & 0.01 & 0.12 & 0.01 & 0.12 & 0.01 & 0.02 \\
\hline Mercurio $(\mathrm{mg} / \mathrm{L})$ & 0.001 & 0 & 0.0002 & 0 & 0.0001 & 0 \\
\hline Plomo (mg/L) & 0.005 & 0 & 0.008 & & 0.007 & \\
\hline
\end{tabular}

Tabla 8 Evolución histoórica de calidad del agua en el CUCBA

Fuente: Elaboración Propia

\section{Conclusiones}

No se presentaron parámetros fuera de norma, solo la presencia de coliformes totales con $33 \%$ y fecales con el $13 \%$ de muestras, y no hubo presencia de metales pesados. El agua de la fuente de abastecimiento tuvo un ICA que corresponde a una clasificación de aceptable ya que los parámetros fisicoquímicos se encontraron con valores dentro de la NOM127-SSA1-1994 y de Criterios Ecológicos.

La Calidad del agua de la red se considera deficiente y no apta para consumo humano, ya que se encontró la presencia de organismos Coliformes totales y fecales, y que rebasan el límite permisible establecido en la NOM- 127-SSA1-1994 y de Criterios Ecológicos. En la red de distribución del CUCBA, los valores de nitrógeno de nitritos y nitratos, el $\mathrm{pH}$ y metales pesados como Cadmio, Hierro, Manganeso y Plomo, se encontraron dentro de los límites permisibles establecidos en la NOM- 127-SSA1-1994 y no representan daño a la salud, lo que evidencia puntos de infiltración a la red de distribución.

GARCÍA-VELASCO, Javier, VILLASEÑOR-VARGAS, Tania, CASAS-SOLÍS, Josefina y ROSAS-RAMÍREZ, Aurora. Calidad del agua de distribución en un Centro Universitario rural sin procesos de desinfección de la Universidad de Guadalajara, México. Revista del Desarrollo Urbano y Sustentable. 2019 
Se debe reforzar el monitoreo de puntos de uso intensivo del agua como bebederos y zona de resytaurant, ya presentan carga bacteriológica elevada debiendo solucionarse y describir los focos contaminantes.

Se debe eficientar la depuraciones de las aguas residuales en niveles que exige la normativa, ya que la disposición final de estas es a pozos de absorción, que pueden contaminar el acuífero principal. Además de que no existe separación de aguas residuales de laboratorios, lo que impacta negativamente a los procesos de depuración de aguas residuales que trabajan por lodos activados.

Finalmente dse debe exigir la aplicación de procesos de desinfeccion del agua una vez que sale de los pozos de extraccion, dado que es evidente la contaminacion en el sistema de distribución.

\section{Referencias}

APHA, AWWA, WPCF. Métodos Normalizados para el Análisis de Aguas Potables y Residuales. 1998. 20th Edición.

APHA-AWWA-WPCF. 1992. Métodos Normalizados para el Análisis de Aguas Potables y Residuales. Editorial Díaz de Santos. España.

Ballester F. 1995. Estrategias encaminadas a conseguir ambientes sanos. Boletín de la Sociedad Española de Sanidad Animal. 1: 7-10.

Chávez A. M. E. 1995. El agua y su importancia en la salud. Boletín de Salud Ambiental Universidad de Guadalajara. 1: 4446.

G. Martínez de Bascaran: Estudio de un Índice de Polución para calificar la calidad del agua; "Revista de Obras Públicas" 210, juny 1 975. J. M. Landwehr: A comparation ofseveral Water Quality Indexes; maig 1976.

Guzman, A. \& Merino, E. (1992). El Lago de Chapala. Information básica. Universidad de Guadalajara. Inst. De limnología. Chapala, Jalisco. 12 pp.
López Illan, Y. (2001). Evaluación de la calidad del agua e identificación de riesgos en el centro universitario de ciencias biológicas y agropecuarias. Maestría. Universidad de Guadalajara.

Ordenamiento Ecológico Territorial. 1997. Universidad de Guadal ajara.

Martínez de Bascaran, G. (1979). Establecimiento de una Metodología para conocer la Calidad del Agua. Bol. Inf. Medio Ambiente, 9:30-51.

Nisbet, M.; Verneaux, J. (1970). Composantes Chimiques Des Eaux Courantes. Ann. Limnol. 2.

NOM-014-SSAl-1993. Procedimientos sanitarios para el muestreo de agua para uso y consumo humano en el sistema de abastecimiento de agua públicos y privados. Diario Oficial de la Federación, 12 de agosto de 1994.

NOM-127-SSA1-1994, Salud ambiental. Agua para uso y consumo humano. Límites permisibles de calidad y tratamientos a que debe someterse el agua para su potabilización.

NOM-230-SSA1-2002, Salud ambiental. Agua para uso y consumo humano, requisitos sanitarios que se deben cumplir en los sistemas de abastecimiento públicos y privados durante el manejo del agua. Procedimientos sanitarios para el muestreo.

Mariscal, L.A. et al. 1995. Estudio Sanitario de Agua. Universidad de Valencia España.

SAWYER, MCCARTHY, \& PARKIN. (2001). QUIMICA PARA INGENIERIA AMBIENTAL (4 ${ }^{\mathrm{a}}$ ED.). Bogotá: MCGRAWHILL.

Secretaría de Recursos Hidráulicos. 1973. Dirección de Aprovechamientos Hidráulicos. Laboratorio en Guadalajara.

UNESCO. (05 de 03 de 2003). La inercia política exacerba la crisis del agua, según el informe mundial sobre recursos hídricos. Recuperado el 03 de 07 de 2018, de http://portal.unesco.org/es/ev.php-

URL_ID=10064\&URL_DO=DO_TOPIC\&UR L_SECTION=201.html 
OMS. (2003). INFORME SOBRE LA SALUD EN EL MUNDO 2003. Francia: Marilyn Langfeld.

Rojas, M. (2011). Estudios de la contaminación de los recursos hídricos en la cuenca del rio San Pedro, previos a la construcción de una hidroeléctrica. Universidad de Guadalajara 